\title{
Household knowledge and practices concerning malaria and indoor residual spraying in an endemic area earmarked for malaria elimination in Iran
}

\author{
Abdoulhossain Madani ${ }^{1}$, Moussa Soleimani-Ahmadi ${ }^{1}{ }^{2 *}$, Sayed Hossein Davoodi ${ }^{3}$, Alireza Sanei-Dehkordi ${ }^{2}$,
} Seyed Aghil Jaberhashemi ${ }^{4}$, Mehdi Zare ${ }^{5}$ and Teamur Aghamolaei ${ }^{1}$

\begin{abstract}
Background: Indoor residual spraying of insecticide (IRS) is a key intervention for reducing the burden of malaria infection. Effectiveness and success of this strategy are to a considerable extent dependent on knowledge and practice of the target community regarding the IRS. Iran has entered the malaria elimination phase, and IRS has been considered as the main strategy for malaria vector control. Therefore, this study was conducted to determine the household knowledge and practices about malaria and IRS in Bashagard County, one of the malaria-endemic areas in the southeast of Iran.

Methods: A community-based cross-sectional survey was conducted among 420 households in Bashagard County. The participants who were selected using a two-stage randomized cluster sampling procedure were subjected to a tested structured questionnaire. During the survey, direct observations were made concerning the use of IRS as well as housing conditions. The data were coded and analysed using SPSS version 19.

Results: Knowledge levels about malaria as a disease and the mosquito as its vector were high and of equal magnitude (85.5\% and $85.4 \%$, respectively), while knowledge levels of IRS were even higher (91.6\%). The main source of households' information about malaria and IRS was primarily community health workers (73.3\%). Despite positive perceptions towards IRS only $26.7 \%$ of respondents had sprayed their houses which is lower than the WHO targeted coverage of $80 \%$. Respiratory disorders and headache (33.3\%), food contamination (24.9\%), discolouring of inner house walls (17.7\%), difficulty in furniture's movement (13.8\%), and unpleasant odour (10.4\%) were the main reasons for IRS refusal.

Conclusion: There is a discrepancy between knowledge about symptoms and the transmission route of malaria and control practices related to IRS use. Therefore, IRS campaigns accompanied with education for behaviour change should be considered to ensure householders' participation and cooperation in the IRS programme. Moreover, continuous evaluation and monitoring of IRS as well as conducting more surveys on knowledge, attitude, and practices are recommended to improve malaria control measures and to identify indicators for effective, successful, and sustainable malaria elimination programme.
\end{abstract}

Keywords: Malaria, Knowledge, Practices, Household, Indoor residual spraying, Iran

\footnotetext{
* Correspondence: mussa.sahmadi@gmail.com; mussa.soleimani@yahoo.com

${ }^{1}$ Social Determinants in Health Promotion Research Center, Hormozgan University of Medical Sciences, Bandar Abbas, Iran

${ }^{2}$ Department of Medical Entomology and Vector Control, Faculty of Health,

Hormozgan University of Medical Sciences, P.O. Box: 79145-3838, Bandar

Abbas, Iran

Full list of author information is available at the end of the article
} 


\section{Background}

Malaria remains a major contributor to worldwide disease burden and is currently endemic in 91 countries [1]. In 2015, approximately 212 million new cases of malaria were diagnosed, and about 429,000 people died from malaria worldwide [1].

In Iran, the malaria eradication campaign was initiated in 1951 and changed to malaria control in 1985 as a result of constraints and challenges [2]. Iran has been in the current elimination phase since 2010. In 2009, the number of malaria cases in Iran were 6122, and it was reduced to 720 in 2015 [1, 3].

Iran, as in other malaria-endemic countries, has employed effective vector control measures including indoor residual spraying (IRS), long-lasting insecticidal nets (LLINs), and application of larvicides as the main vector control interventions [4-6]. Challenges to the elimination of malaria in low socioeconomic areas, such as Bashagard County, include the inability to sustain control programmes due to community perceptions and practice for malaria control. Promotion of community participation through health education and communication programmes can be considered as a strategy against these challenges.

IRS is the large-scale application of insecticides to spray the interior of homes for killing mosquitoes. It remains one of the main components of the malaria control strategy, which aims to prevent parasite transmission through interventions targeting Anopheline vectors [7, 8]. IRS has been employed to eliminate malaria from different malaria endemic areas including Europe, Asia, Latin America, and Africa [9]. National malaria control programmes in the 91 endemic countries reported that 106 million people worldwide were protected by IRS in 2015 [1]. Several factors which influence the effectiveness of IRS interventions include spraying coverage, type of insecticide, type and situation of houses, community awareness and cooperation, household acceptance, and informing the households about the programme benefits and spraying time during the spraying campaign [10]. Spraying coverage is also dependent on the household's perception of the effectiveness of IRS programme against mosquitoes and other nuisance insects, as well as the number and intensity of unwanted side effects [8]. The perceived side effects of indoor insecticide spraying can decrease the acceptance of these types of interventions [11]. It is thus necessary to understand community knowledge about house spraying for the IRS programmes to be successful [12].

Previous studies have demonstrated that communities have positive expectations when interventions such as IRS are introduced [8, 11]. However, they may refuse IRS due to their concerns about IRS with regards to chemicals being a health hazard or doubts about its effectiveness $[11,13]$.
According to the recent reports, almost all areas of Iran are considered as malaria-free, except some regions in the south-east of the country which are still considered as endemic malaria area [1, 14]. Bashagard is one of the malaria-endemic regions in this area with two seasonal peaks in autumn and spring. In this county 1406 cases of malaria were reported during 2008-2015, out of which $1394(99.15 \%)$ and $12(0.85 \%)$ cases were attributed to Plasmodium vivax and $P$. falciparum, respectively (Bashagard Health Center, unpublished data, 2015). Six species including Anopheles stephensi, An. fluviatilis, An. dthali, An. culicifacies, An. superpictus and An. pulcherrimus have been reported as malaria vectors in this County $[15,16]$. One of the WHO recommended strategic approaches for malaria elimination by the use of indoor residual spraying programmes which are highly dependent on pyrethroid insecticides [4]. Regarding this recommendation, IRS has been focused on, by Iranian Ministry of Health and Medical Education as the main component of the malaria vector control intervention strategy [7]. The target of National Malaria Control Programme is to cover at least $85 \%$ of all targeted households to achieve community coverage sufficient to interrupt transmission of malaria [1].

Community participation is the key component of malaria elimination programmes, and improved community knowledge of malaria control methods can promote preventive practices against malaria $[14,17]$. To achieve efficient IRS coverage, a key factor is identifying and addressing the behavioural factors that may lead to IRS refusal. Increasing the community knowledge about malaria and IRS will lead to behavioural changes which would help in designing sustainable malaria control programmes [13]. In line with assuring for sustainability of the malaria elimination programme in Iran, this study was conducted to determine the community knowledge and practice about malaria and IRS, as a preventive strategy, in Bashagard County, southeast of Iran.

\section{Methods}

Study area

Bashagard County is located between $26^{\circ} 04^{\prime}-26^{\circ} 58^{\prime} \mathrm{N}$ latitudes and $57^{\circ} 23^{\prime}-59^{\circ} 02^{\prime} \mathrm{E}$ longitudes in Hormozgan province, southeastern Iran, with an estimated population of 40,037 individuals in 2015. The climate in Bashagard is categorized as tropical dry, with mean annual temperature of $28.4{ }^{\circ} \mathrm{C}$ ranging from $18.8{ }^{\circ} \mathrm{C}$ to $37.4{ }^{\circ} \mathrm{C}$, and a relative humidity between 18 and $38 \%$. The average annual rainfall is about $251 \mathrm{~mm}$ (Fig. 1). Water bodies such as rivers and streams normally exist in the area. The county is mostly mountainous and hilly, with scattered population inhabited mainly close to rivers. The villages are small and relatively difficult to access with a low population who live in houses made of cement blocks and shelters (Fig. 2). 


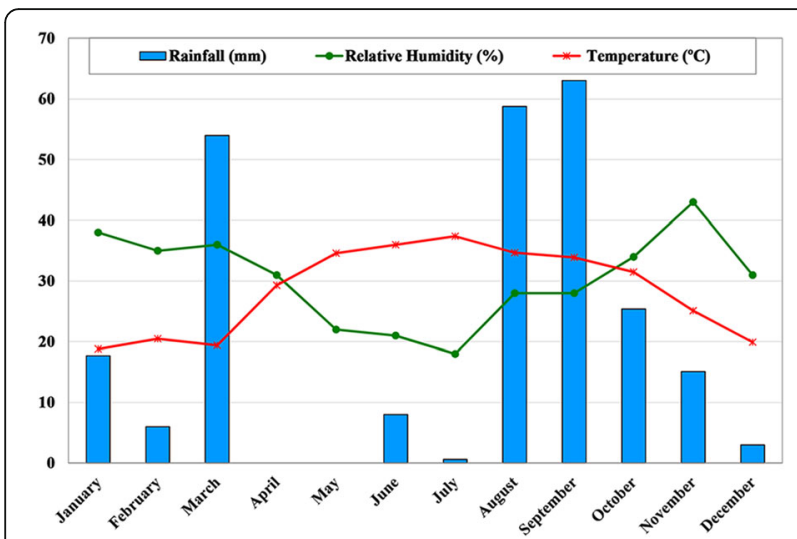

Fig. 1 Average of meteorological parameters during 2015-2016 in Bashagard County, southeastern Iran

Farming and livestock herding are the main economic activities in this County. Malaria transmission occurs in this area year-round with peaks after the two rainy seasons (April-June and October-December), and Plasmodium vivax accounts for the majority of malaria cases [16]. In this region, IRS activities began in 1953, and since then at least two campaigns per year has taken place [2].

\section{Study design}

This community-based cross-sectional study was conducted between January and March 2016 in Bashagard County.

\section{Sample size calculation}

Assuming expected knowledge regarding malaria and IRS to be $50 \%$ and the desired precision of $5 \%$, the sample size determined to be 420 [18].

\section{Data collection}

Inclusion criteria included being a permanent member of the community, being an adult (a woman or head of the household), and being resident in the sprayed houses. The exclusion criteria were being unable to communicate normally and non-cooperative households who refused to furnish necessary information. A twostage randomized cluster sampling procedure was used to select the participants. In the first stage, six villages with similar epidemiological and topographical characteristics, where IRS has been ongoing, were randomly selected (Fig. 3). In the next stage, 70 households were selected from each village randomly. Since the fathers of families were mostly out of the house to work, mothers were interviewed using a pre-tested structured questionnaire. In case that mothers were absent, another adult member was interviewed instead. Questionnaires were filled via face-to-face interviews conducted by trained research assistants and supervised by the chief investigator.

The questions included respondents' sociodemographic characteristics and knowledge and practices about malaria and IRS focusing on malaria symptoms and transmission, IRS coverage, the frequency of spraying, and positive and negative effects of the IRS programme.
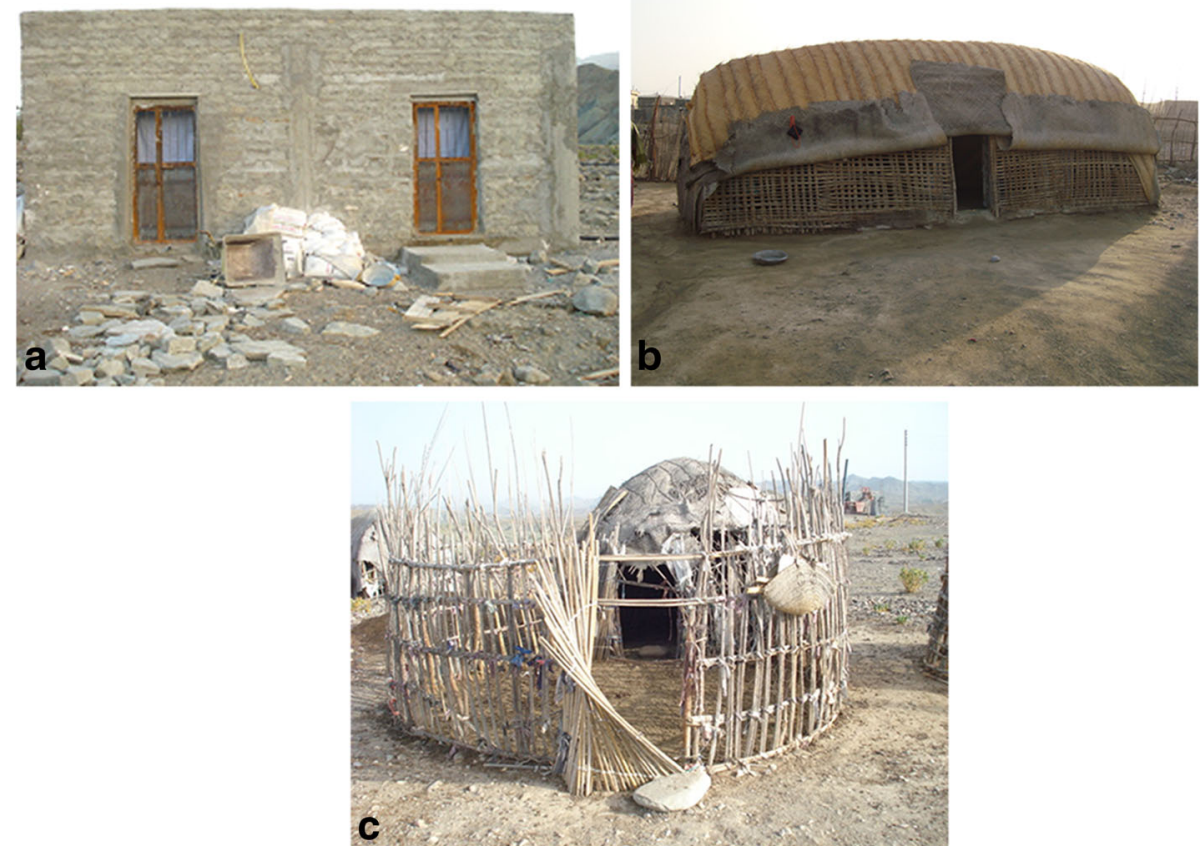

Fig. 2 Typical habitats of human and animal in Bashagard County, southeastern Iran. Cemented brick houses (a), sheds made with palm leaves (b) and domestic animal shed (c) 


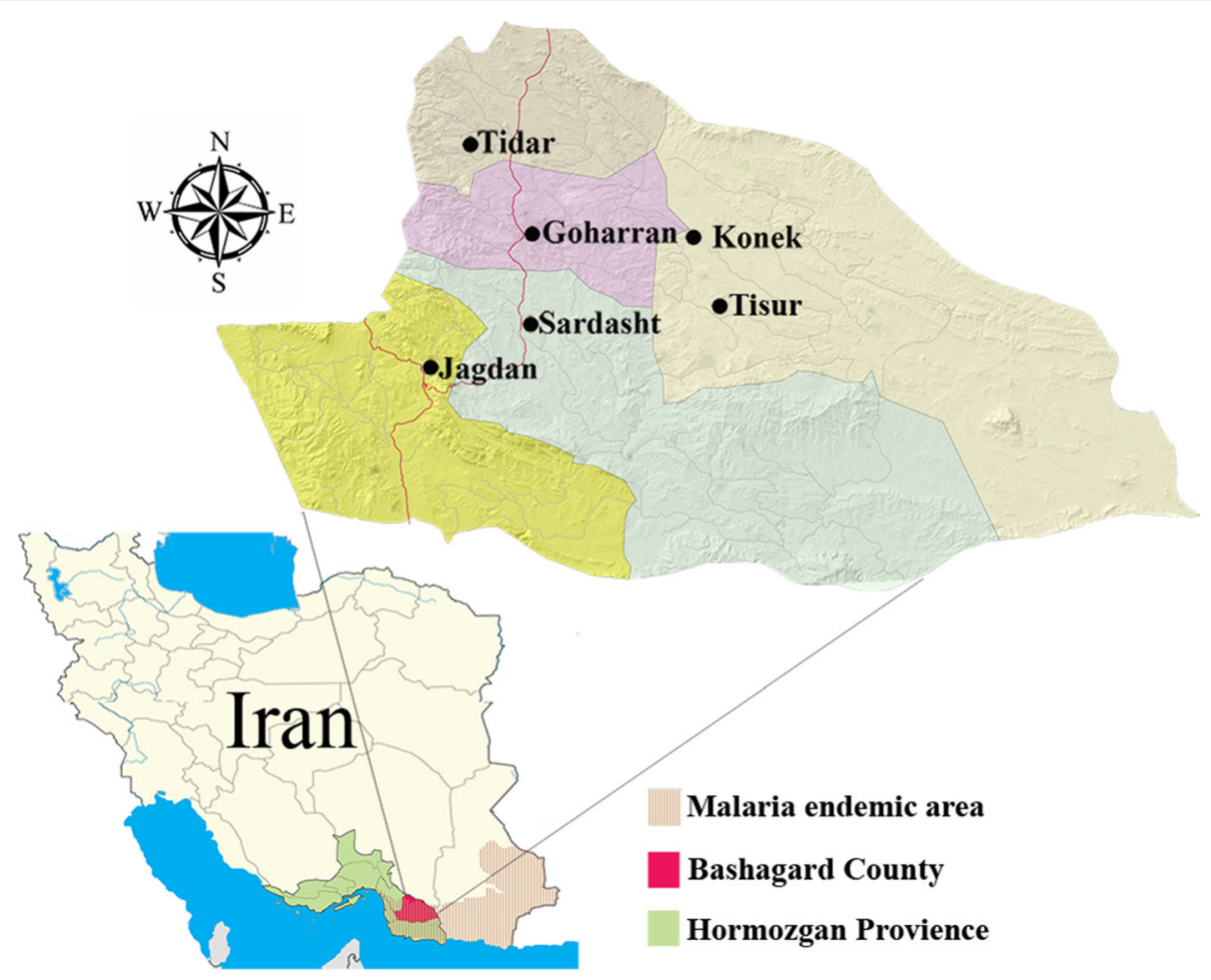

Fig. 3 Map showing the provinces of Iran, highlighting the location of endemic malaria areas, and study villages in Bashagard County of Hormozgan Province, southeastern Iran

As part of the data collection process, a checklist was completed through direct observations to investigate the use of IRS as well as housing conditions including water containers, indoor plumbing, construction materials, and status of windows.

\section{Statistical analysis}

The data were coded and then analyzed using SPSS version 19. Descriptive statistics were used to determine averages, relative frequencies and percentages of the variables. Chi-square test was used to determine the association between the knowledge and practice regarding malaria and IRS and different variables. The results were considered significant at $5 \%$ levels of significance $(P<0.05)$.

\section{Results}

\section{Socio-demographic characteristics}

A total of 420 households participated in this study. The age of participants ranged from 17 to 75 years with an average of 29.8 years. The majority of the women had no formal education $(55.8 \%$ ), and $32.3 \%$ had completed primary school education. Most of the participants (96.5\%) were unemployed and engaged in housework; others were self-employed, farmer/stockbreeder, and office workers. The average family size was 4.9 individuals and ranged from 1 to 11 people. Socio-demographic characteristics of the study population are illustrated in Table 1.

About $42 \%$ of households had a home constructed of cement blocks, and $8.3 \%$ of houses had screens over the window openings (Table 2). More than half of the participants were living in sheds which were made of palm leaves (56.8\%), where domestic animals were mostly kept in the sheds (86.4\%). About half of the population (50.7\%) had access to piped water, $91.7 \%$ had electricity in their houses, and $60.4 \%$ had cooler (evaporative cooler or air conditioner) in their houses. More than half of the houses $(62.5 \%)$ were built within $20 \mathrm{~m}$ of domestic animal shelters such as chickens, goats, and sheep (Table 2).

\section{Malaria knowledge and practices}

The majority of the study population (85.5\%) knew about malaria as a disease, and $85.4 \%$ of them knew that malaria is transmitted through a mosquito bite and level of knowledge was significantly associated with the level of education $\left(\chi^{2}=3.41, d f=4, P=0.03\right)$ (Table 3). This study showed that some respondents had misunderstandings about malaria transmission causes considering the responses such as eating contaminated food, drinking dirty water, and inhaling polluted air they gave (Table 3).

The most commonly mentioned symptoms of malaria were fever (81.1\%), followed by a chill, joint/muscle pains, and nausea (Table 3). About half of the respondents 
Table 1 Socio-demographic characteristics of the study population in Bashagard County, southeastern Iran

\begin{tabular}{|c|c|c|}
\hline Characteristics & $n$ & Percent \\
\hline \multicolumn{3}{|l|}{ Age groups (years) } \\
\hline $15-24$ & 66 & 15.6 \\
\hline $25-34$ & 126 & 29.7 \\
\hline $35-44$ & 98 & 23.1 \\
\hline $45+$ & 134 & 31.6 \\
\hline \multicolumn{3}{|l|}{ Education } \\
\hline Illiterate & 247 & 58.3 \\
\hline Primary & 142 & 33.5 \\
\hline Secondary & 10 & 2.4 \\
\hline High school & 17 & 4.0 \\
\hline University & 8 & 1.9 \\
\hline \multicolumn{3}{|l|}{ Family size } \\
\hline $1-2$ & 55 & 13.0 \\
\hline $3-4$ & 138 & 32.5 \\
\hline $5-6$ & 133 & 31.4 \\
\hline $7+$ & 98 & 23.1 \\
\hline \multicolumn{3}{|l|}{ Occupation } \\
\hline Housewife & 409 & 96.5 \\
\hline Employed & 4 & 1.0 \\
\hline Self-employed & 9 & 2.1 \\
\hline Farmer/Stockbreeder & 2 & 0.4 \\
\hline
\end{tabular}

(53.3\%) mentioned having experienced cases of malaria infection in their family within the past 5 years (Table 3 ). The households who had a case of malaria infection in their family had a better knowledge of malaria symptoms compared to those with no history of malaria infection $\left(\chi^{2}=7.26, d f=4, P=0.01\right)$.

Table $\mathbf{2}$ Characteristics of residence houses in the study area in Bashagard County, southeastern Iran

\begin{tabular}{|c|c|c|c|c|}
\hline \multirow[t]{2}{*}{ Characteristics } & \multicolumn{2}{|c|}{ Response: Yes } & \multicolumn{2}{|c|}{ Response: No } \\
\hline & $n$ & Percent & $n$ & Percent \\
\hline \multicolumn{5}{|l|}{ Type of house } \\
\hline Shed & 241 & 56.8 & 183 & 43.2 \\
\hline Cement block house & 179 & 42.2 & 245 & 57.8 \\
\hline Tent & 4 & 1.0 & 420 & 99.0 \\
\hline \multicolumn{5}{|l|}{ Situation of house } \\
\hline Window screens & 35 & 8.3 & 389 & 91.7 \\
\hline Water supply & 215 & 50.7 & 209 & 49.3 \\
\hline Water saving container & 239 & 56.4 & 185 & 43.6 \\
\hline Electricity & 389 & 91.7 & 35 & 8.3 \\
\hline Air conditioner & 256 & 60.4 & 168 & 39.6 \\
\hline Animal shelter close to house & 265 & 62.5 & 159 & 37.5 \\
\hline
\end{tabular}

Table 3 Knowledge and practices regarding malaria in the study population in Bashagard County, southeastern Iran

\begin{tabular}{lll}
\hline Parameters & $n$ & Percent \\
\hline Malaria transmission & 362 & 85.4 \\
Mosquito bites & 19 & 4.5 \\
Drinking dirty water & 11 & 2.6 \\
Eating contaminated food & 8 & 2.0 \\
Inhaling polluted air & 32 & 7.5 \\
Do not know & & \\
Malaria symptoms & 344 & 81.1 \\
Fever & 58 & 13.7 \\
Chill & 19 & 4.5 \\
Bone pain & 3 & 0.7 \\
Nausea & 226 & 53.3 \\
History of malaria infection in family members & & \\
Mosquito breeding places & 318 & 75.0 \\
Stagnant water & 64 & 15.1 \\
Garbage & 37 & 8.7 \\
Do not know & 5 & 1.2 \\
Others & & \\
Malaria preventive measures & 205 & 48.8 \\
Use of long-lasting insecticidal nets & 144 & 34.3 \\
Use of indoor residual spraying & 25 & 6.0 \\
Use of door/window screens & 21 & 5.0 \\
Chemoprophylaxis & 10 & 2.4 \\
Others & 318 & 75.0 \\
Noting & & \\
Interesting in participation in malaria control programmen & & \\
& &
\end{tabular}

Stagnated water considered by the majority of the respondents (75\%) as breeding place of mosquitoes, although garbage also was mentioned as a breeding place (Table 3). Statistical analysis revealed a significant association between correct knowledge of mosquito breeding places and educational level of households $\left(\chi^{2}=4.28, d f=\right.$ 2, $P=0.001)$.

More than half (56.4\%) of households reported they stored drinking water in containers inside the houses and $82 \%$ of them reported that they covered the water containers. The majority of respondents (83.3\%) had LLINs, and approximately 69\% reported that they covered the windows using mosquito screen.

Most of the participants reported LLINs, IRS, the screen on doors/windows, and chemoprophylaxis as preventive measures against malaria transmission (Table 3). The proportion of households with higher levels of knowledge on prevention and transmission of malaria that used preventive measures was significantly higher than in households with lower knowledge. 
Community health workers were reported to be the main source of households' information about malaria and IRS. Other information sources were mass media including television, radio, newspapers, and books (Fig. 4).

\section{Knowledge and practice regarding IRS}

This study's results showed that most of the respondents (91.6\%) had previously heard that insecticides were used for IRS. Out of those who had heard of IRS, $88.2 \%$ reported that IRS would be beneficial. A significant association was found between IRS acceptability and malaria knowledge of respondents $\left(\chi^{2}=6.42, d f=2, P=0.002\right)$. In addition, most of the respondents (73.1\%) mentioned that IRS should be conducted every six months and $1.9 \%$ said they did not know the frequency of IRS. Details of spraying frequency are shown in Table 4.

The results also showed that $26.7 \%$ of all the surveyed households had been sprayed in the previous summer and out of them, $65.6 \%$ reported that spraying was useful. The majority of the participants $(96.6 \%)$ reported that several days before the spraying, they had received information about the IRS campaigns and community health workers were the main source of their information (67.8\%).

Protection against anopheline mosquito bites was reported to be the main reason for using IRS (82.1\%). The other reasons were protection against other insects' nuisance (10\%), and scorpion stings (5.7\%) and a few of the respondents $(2.1 \%)$ reported that they did not know the importance of IRS application. The results revealed that there was a significant association between IRS acceptability and the level of education of households $\left(x^{2}=8.62, d f=6, P=0.02\right)$. Some of the perceived negative health effects of IRS were an unpleasant odour, respiratory disorders, and headache. Difficulty in furniture's movement, discolouring of inner house walls by

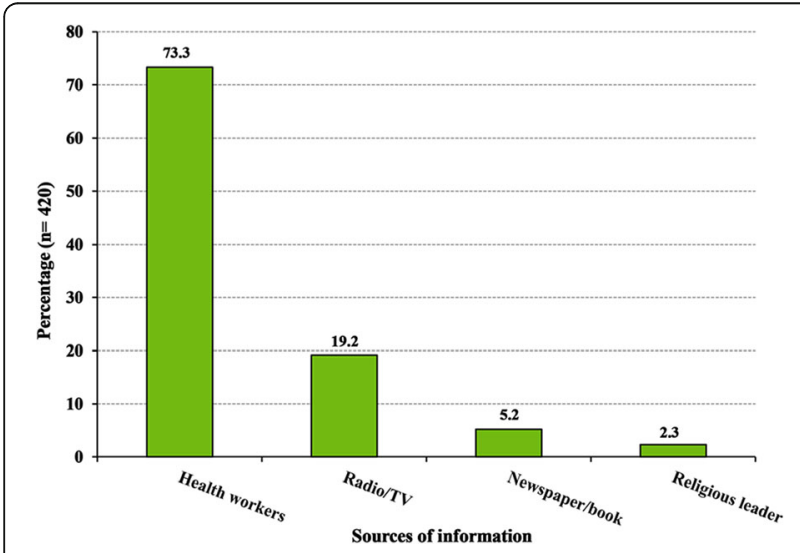

Fig. 4 Sources of information about malaria and IRS in the study population in Bashagard County, southeastern Iran insecticide, and contaminating the foods were other reported reasons for IRS refusal (Fig 5).

About $43 \%$ of study populations lived in simple houses made of cemented bricks with plastered cement walls. Most of the plastered cement walls (82.3\%) were smooth with surfaces that lent themselves well to insecticide treatment. The results of the analysis indicated a significant relationship between the IRS acceptability and building materials $(P<0.001)$. Out of all households, $54.2 \%$ who were living in cemented brick buildings rejected IRS campaign. The exact parts of the houses to be sprayed with the insecticides are shown in Table 4. In this regard, most of the respondents (47.1\%) mentioned that the surfaces of inner walls and roof should be sprayed.

According to the results, most of the respondents (75\%) were interested in taking part in IRS campaign voluntarily (Table 3 ). A statically significant relationship was observed between the educational levels of households and their interest in participating in IRS programme as a volunteer $\left(\chi^{2}=4.12, d f=4, P=0.032\right)$.

\section{Discussion}

This study was conducted to provide baseline information on knowledge and practices regarding malaria and IRS which can be used in decision-making processes, the design of sustainable interventions with active community participation, and the implementation of educational programmes towards the prevention and control of malaria.

This study showed a high level of knowledge about malaria transmission and symptoms in the study population. Similar findings have also been reported from other malaria-endemic areas in the southeast of Iran [10, 14, 19]. Also, high awareness of people about malaria transmission and symptoms has been reported from other malariaendemic countries including Malaysia, Saudi Arabia, Swaziland, Ethiopia, Ghana and Tanzania [17, 20-24].

Results of this study showed that Community Health Workers were the main source of household's information about malaria and IRS. This finding is consistent with findings in other studies from different malaria endemic regions around the world which indicates that Community Health Workers are frequently in contact with people [21, 25, 26]. This is in contrast to findings from a recent study conducted in Saudi Arabia, India and Uganda that reported the social media as the primary source of malaria information $[20,27,28]$. Access to Community Health Workers and communication facilities had previously been reported to play an important role in prevention and control of malaria [29].

This study revealed a significant relationship between knowledge levels of the households about malaria symptoms and the history of malaria infection in the family. High awareness of the symptoms of malaria, which is a key to seeking early treatment, has been reported in 
Table 4 Knowledge and practices regarding IRS in the study population in Bashagard County, southeastern Iran

\begin{tabular}{|c|c|c|}
\hline Parameters & $n$ & Percent \\
\hline \multicolumn{3}{|l|}{ Ever heard of IRS } \\
\hline Yes & 385 & 91.6 \\
\hline No & 35 & 8.4 \\
\hline \multicolumn{3}{|l|}{ Frequency of spraying } \\
\hline Once in four months & 26 & 6.2 \\
\hline Once in six months & 307 & 73.1 \\
\hline Once a year & 79 & 18.8 \\
\hline Do not know & 8 & 1.9 \\
\hline \multicolumn{3}{|l|}{ Importance of IRS } \\
\hline Prevention of mosquito nuisance & 345 & 82.1 \\
\hline Prevention of other insects nuisance & 42 & 10.0 \\
\hline Prevention of scorpion stings & 24 & 5.7 \\
\hline Others & 9 & 2.1 \\
\hline \multicolumn{3}{|l|}{$\begin{array}{l}\text { The exact parts of the house to be sprayed } \\
\text { during IRS }\end{array}$} \\
\hline On the surfaces of inner walls and roof & 198 & 47.1 \\
\hline On the surfaces of inner walls & 135 & 32.1 \\
\hline On the surfaces of outer walls & 31 & 7.4 \\
\hline On the inner surfaces of the roof & 44 & 10.5 \\
\hline Do not know & 12 & 2.9 \\
\hline $\begin{array}{l}\text { Interesting in participation in IRS programmes } \\
\text { as a volunteer }\end{array}$ & 318 & 75.0 \\
\hline
\end{tabular}

populations in endemic malaria areas where people frequently suffer from malaria infection [25, 30, 31]. Understanding the treatment-seeking behaviours in populations will assist in identifying the possible barriers to surveillance and response activities that might exist such as reasons for delays in diagnosis and treatment. Moreover, understanding community behaviour about treatmentseeking will assist in the sustained community and health

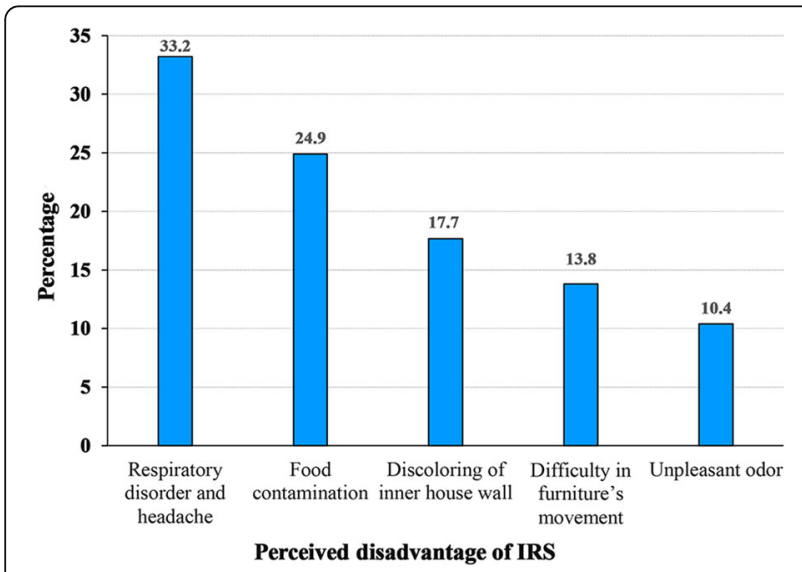

Fig. 5 Dissatisfaction rate of the study population regarding IRS in Bashagard County, southeastern Iran system efforts that will be required to prevent the resurgence of malaria following elimination [32].

In this study, the majority of the participants knew that mosquitoes transmit malaria and awareness about malaria transmission were positively associated with the age and seeking treatment. High levels of awareness about malaria transmission in the studied area can be explained by long-term exposure to malaria over the years and receiving information from health workers. Contrary to these findings, in other malaria-endemic countries such as Malaysia and Malawi only those with a higher level of education knew about the symptoms and vector of malaria $[17,33]$. In this regard, results of some studies indicate that improving the community's knowledge of malaria transmission can greatly contribute to prevention and success of control measures [17, 34].

Results of this study revealed that majority of the participants knew stagnated water as a breeding place of malaria vectors. This finding is consistent with findings in other studies in Iran which revealed high knowledge of people about mosquitoes breeding places [14, 35]. Similar results have been reported from other malariaendemic countries such as Tanzania, and India [36, 37]. Awareness of mosquitoes breeding site could influence parameters which are involved in the vector control including the selection of residential areas and use of preventive methods aiming to decrease mosquito population density.

According to the results, more than half of households lived in poorly constructed houses and lacked window mosquito screens. Poor and inappropriate housing conditions have been proved to be associated with insufficient mosquito protection practices and a higher risk of malaria infection $[25,34]$. Other studies have shown that in areas with low to moderate transmission, improving house design and using mosquito screens decreases mosquito densities and reduces malaria transmission $[38,39]$. Furthermore, mosquito screens for houses are an appropriate, affordable, long-lasting, and acceptable protection method used in different communities [40].

This study indicated that despite having positive perceptions towards IRS, a large number of participants in the study population did not apply it. In this regard, $82.1 \%$ of the studied population mentioned IRS as an effective preventive measure against malaria vector, but only $26.7 \%$ of the houses had been sprayed as reported by the participants. This rate of IRS coverage is lower than $80 \%$ which is the targeted coverage by WHO [4]. Although this rate of IRS coverage is more than previously reported data from Iran [19], it is considerably lower than those reported form other malaria-endemic countries, such as Swaziland, Mozambique, Namibia, and Haiti [21, 41-43]. Therefore, the IRS coverage in the study area is much lower than the level required for effective control of the malaria vector. 
According to our results, one of the explanations for such low IRS coverage can be a negative perception about it due to suspected IRS negative health effects, difficulty in furniture's movement, and discolouring of inner house walls by insecticides. These results are consistent with the findings from other studies that reported insecticide smell, the mess left by the sprayers, the inconvenience of removing household items from houses before spraying as the causes of IRS refusal [44]. Moreover, other causes of IRS refusal have been reported to be poisoning of domestic animals, poisoning of children, and infertility of family [45]. Another reason for low IRS coverage in this study, as it has been reported from endemic malaria areas in Uganda, Yemen and South Sudan, can be the perceived low susceptibility and exposure to malaria infection as well as the perceived low severity of malaria infection in the community $[44,46,47]$.

The effectiveness of IRS in malaria control is the main reason Iran adopted IRS as the main control strategy. However, it is of concern that IRS coverage was very low in the study population. This is especially so in light of the malaria elimination phase status which Iran carries. Therefore, efforts should be made for increasing the IRS coverage through promoting the attitude and practice of households regarding IRS for effective malaria control.

\section{Conclusion}

There is a discrepancy between knowledge about symptoms, transmission route and control of malaria and use of IRS. Low socio-cultural and socio-economic status of the community are the main limitations to sustainable malaria elimination. These factors, along with community attitudes and practices, ultimately influence community participation in malaria elimination despite high knowledge. There is need to facilitate correct attitudes towards IRS use in Bashagard county if the disparity between knowledge and use should be bridged. Therefore, IRS campaigns accompanied with education for behaviour change should be considered as key elements for malaria control in the studied population. Moreover, continuous monitoring and evaluation of IRS and conducting more surveys on knowledge, attitude and practices are recommended to improve malaria control measures and to identify indicators for successful and sustainable malaria elimination programme.

\section{Abbreviations}

IRS: Indoor residual spraying; LLINs: Long-lasting insecticidal nets

\section{Acknowledgements}

The authors would like to appreciate the collaboration received from Dr Darakhshan, Head of Bashagard Health Center for his logistic support for collecting samples. We are also thankful to personnel of the Bashagard Health Center for their cooperation in the field. This study received financial support from Research Deputy of Hormozgan University of Medical Sciences (Project.

No. 586).
Funding

This research has been funded by Research Deputy of Hormozgan University of Medical.

Sciences (Project No. 586).

\section{Availability of data and materials}

The datasets supporting the conclusions of this article are included within the article.

\section{Authors' contributions}

MSA, AM, ASD, SHD and MZ conceived and designed the study. MSA and MZ drafted the manuscript. MSA, AM and TA analysed the data. MSA and SAJ coordinated in field activity, collected data and trained field researcher. All authors read and approved the final manuscript.

\section{Ethics approval and consent to participate}

The participants were informed about the objectives and procedures of the investigation. They signed an informed consent document to ensure the willingness of participation and they were free to withdraw from the study at any time. Identification numbers were used instead of participant names to maintain the confidentiality throughout the study. This study has been registered and approved by Hormozgan University of Medical Sciences Ethical Committee (No. 586). Study registration date: November 25, 2014.

Consent for publication

Not applicable.

Competing interests

The authors declare that they have no competing interests.

\section{Publisher's Note}

Springer Nature remains neutral with regard to jurisdictional claims in published maps and institutional affiliations.

\section{Author details}

${ }^{1}$ Social Determinants in Health Promotion Research Center, Hormozgan University of Medical Sciences, Bandar Abbas, Iran. ${ }^{2}$ Department of Medical Entomology and Vector Control, Faculty of Health, Hormozgan University of Medical Sciences, P.O. Box: 79145-3838, Bandar Abbas, Iran. ${ }^{3}$ Department of Nutrition Research, National Nutrition and Food Technology Research Institute, Faculty of Nutrition Sciences and Food Technology, Shahid Beheshti University of Medical Sciences, Tehran, Iran. ${ }^{4}$ Bashagard Health Center, Hormozgan University of Medical Sciences, Bashagard, Iran. ${ }^{5}$ Department of Occupational Health Engineering, Faculty of Health, Hormozgan University of Medical Sciences, Bandar Abbas, Iran.

Received: 11 July 2017 Accepted: 21 November 2017

Published online: 06 December 2017

\section{References}

1. WHO. World malaria report 2016. Geneva: World Health Organization; 2016. http://apps.who.int/iris/bitstream/10665/200018/1/9789241565158_eng.pdf

2. Edrissian G. Malaria in Iran: past and present situation. Iran J Parasitol. 2006; 1 (1):1-4.

3. Sheikhzadeh K, Haghdoost AA, Bahrampour A, Zolala F, Raeisi A. Assessment of the impact of the malaria elimination programme on the burden of disease morbidity in endemic areas of Iran. Malar J. 2016;15:209.

4. WHO: Indoor residual spraying: an operational manual for indoor residual spraying (IRS) for malaria transmission control and elimination. Geneva, World Health Organization; 2015. Available at: http://apps.who.int/iris/ bitstream/10665/177242/1/9789241508940_eng.pdf

5. Sanei-Dehkordi A, Soleimani-Ahmadi M, Akbarzadeh K, Salim Abadi Y, Paksa A, Gorouhi MA, et al. Chemical composition and mosquito larvicidal properties of essential oil from leaves of an Iranian indigenous plant Zhumeria majdae. J Essent Oil Bearing Plant. 2016;19:1454-61.

6. Soleimani-Ahmadi M, Abtahi SM, Madani A, Paksa A, Abadi YS, Gorouhi MA et al. Phytochemical profile and mosquito larvicidal activity of the essential oil from aerial parts of Satureja bachtiarica Bunge against malaria and lymphatic filariasis vectors. J Essent Oil Bearing Plant. 2017;20:328-36. 
7. Zare M, Soleimani-Ahmadi M, Davoodi SH, Sanei-Dehkordi A. Insecticide susceptibility of Anopheles stephensi to DDT and current insecticides in an elimination area in Iran. Parasit Vectors. 2016;9:571.

8. Zaim M, Naseeri-Nejad D, Azoordegan F, Emadi AM. Knowledge and practice of residents about malaria in southeast Iran (1994). Acta Trop. 1997; 64(3-4):123-30.

9. Kaufman MR, Rweyemamu D, Koenker H, Macha J. My children and I will no longer suffer from malaria: a qualitative study of the acceptance and rejection of indoor residual spraying to prevent malaria in Tanzania. Malar J. 2012;11:220.

10. Sakeni M, Khorram A, Majdzadeh R, Raiesi A. Indoor residual spraying coverage and acceptability rates to control malaria and the householders' reasons of acceptance or rejection of spraying, in south-east of Iran. Int J Infect. 2015;2:e31548.

11. Rodriguez AD, Penilla RP, Rodriguez MH, Hemingway J, Trejo A, HernandezAvila JE. Acceptability and perceived side effects of insecticide indoor residual spraying under different resistance management strategies. Salud Publica Mex. 2006;48:317-24.

12. WHO: Use of indoor residual spraying for scaling up global malaria control and elimination, global malaria Programme. A WHO position statement. Geneva, World Health Organization; 2006. Available at: http://apps.who.int/ iris/bitstream/10665/69386/1/WHO_HTM_MAL_2006.1112_eng.pdf

13. Yadav $S$, Kalundha R, Sharma R. Sociocultural factors and malaria in the desert part of Rajasthan. India J Vector Borne Dis. 2007;44:205-12.

14. Soleimani-Ahmadi M, Vatandoost $\mathrm{H}$, Zare M, Alizadeh A, Salehi M. Community knowledge and practices regarding malaria and long-lasting insecticidal nets during malaria elimination programme in an endemic area in Iran. Malar J. 2014;13:511.

15. Soleimani-Ahmadi $M$, Vatandoost $H$, Zare $M$, Turki $H$, Alizadeh $A$. Topographical distribution of anopheline mosquitoes in an area under elimination programme in the south of Iran. Malar J. 2015;14:262.

16. Soleimani-Ahmadi $M$, Vatandoost $H$, Shaeghi $M$, Raeisi $A$, Abedi $F$, Eshraghian MR, et al. Field evaluation of permethrin long-lasting insecticide treated nets $\left(\mathrm{Olyset}^{\oplus}\right)$ for malaria control in an endemic area, southeast of Iran. Acta Trop. 2012;123:146-53.

17. Al-Adhroey AH, Nor ZM, Al-Mekhlafi HM, Mahmud R. Opportunities and obstacles to the elimination of malaria from peninsular Malaysia: knowledge, attitudes and practices on malaria among aboriginal and rural communities. Malar J. 2010;9:137.

18. Lemeshow S, Hosmer DW, Klar J, Lwanga SK. Adequacy of sample size in health studies. Chichester: John Wiley \& Sons; 1990. p. 10.

19. Mohammadi M, Ansari-Moghaddam A, Raiesi A, Rakhshani F, Nikpour F, Haghdost A, et al. Baseline results of the first malaria indicator survey in Iran at household level. Malar J. 2011;10:277.

20. Khairy S, Al-Surimi K, Ali A, Shubily HM, AI Walaan N, Househ M, et al. Knowledge, attitude and practice about malaria in south-western Saudi Arabia: a household-based cross-sectional survey. J Infect Public Health. 2017;10(5):499-506.

21. Hlongwana KW, Mabaso ML, Kunene S, Govender D, Maharaj R. Community knowledge, attitudes and practices (KAP) on malaria in Swaziland: a country earmarked for malaria elimination. Malar J. 2009;8:29.

22. Mitiku I, Assefa A. Caregivers' perception of malaria and treatment-seeking behavior for fewer than five children in Mandura District, West Ethiopia: a cross-sectional study. Malar J. 2017;16:144.

23. Adongo PB, Kirkwood B, Kendall C. How local community knowledge about malaria affects insecticide-treated net use in northern Ghana. Tropical Med Int Health. 2005;10:366-78.

24. Mashauri FM, Kinung'hi SM, Kaatano GM, Magesa SM, Kishamawe C, Mwanga JR, et al. Knowledge, attitudes and practices about malaria among communities: comparing epidemic and non-epidemic prone communities of Muleba district, north-western Tanzania. BMC Public Health. 2010;10:395

25. Bashar K, Al-Amin HM, Reza MS, Islam M, Asaduzzaman, Ahmed TU. Sociodemographic factors influencing knowledge, attitude and practice (KAP) regarding malaria in Bangladesh. BMC Public Health. 2012;12:1084

26. Andrew EV, Pell C, Angwin A, Auwun A, Daniels J, Mueller I, et al. Knowledge, attitudes, and practices concerning malaria in pregnancy: results from a qualitative study in Madang, Papua New Guinea. PLoS One. 2015;10(4):e0119077.

27. Gupta RK, Raina SK, Shora TN, Jan R, Sharma R, Hussain S. A household survey to assess community knowledge, attitude and practices on malaria in a rural population of northern India. J Family Med Prim Care. 2016;5:101-7.
28. Ediau M, Babirye JN, Tumwesigye NM, Matovu JK, Machingaidze S, Okui O, et al. Community knowledge and perceptions about indoor residual spraying for malaria prevention in Soroti district, Uganda: a cross-sectional study. Malar J. 2013;12:170

29. Faye O, Correa J, Camara B, Dieng T, Dieng Y, Gaye O, et al. Malaria lethality in Dakar pediatric environment: study of risk factors. Med Trop. 1998;58:361-4.

30. Ahmed SM, Haque R, Haque U, Hossain A. Knowledge on the transmission, prevention and treatment of malaria among two endemic populations of Bangladesh and their health-seeking behaviour. Malar J. 2009;8:173.

31. Adam I, Omer ESM, Salih A, Khamis AH, Malik EM. Perceptions of the causes of malaria and of its complications, treatment and prevention among midwives and pregnant women of eastern Sudan. J Public Health. 2008;16:129-32.

32. Tynan A, Atkinson JA, Toaliu H, Taleo G, Fitzgerald L, Whittaker M, et al. Community participation for malaria elimination in Tafea Province, Vanuatu: part II. Social and cultural aspects of treatment-seeking behaviour. Malar J. 2011;10:204

33. Ager A. Perception of risk for malaria and schistosomiasis in rural Malawi. Trop Med Parasitol. 1992;43:234-8.

34. Evlampidou I, Danis K, Lenglet A, Tseroni M, Theocharopoulos Y, Panagiotopoulos T. Malaria knowledge, attitudes and practices among migrants from malaria-endemic countries in Evrotas, Laconia, Greece, 2013. Euro Surveill. 2015;20:21208.

35. Soleimani Ahmadi M, Vatandoost $H$, Shaeghi M, Raeisi A, Abedi F, Eshraghian MR, et al. Effects of educational intervention on long-lasting insecticidal nets use in a malarious area, southeast Iran. Acta Med Iran. 2012;50:279-87.

36. Mazigo HD, Obasy E, Mauka W, Manyiri P, Zinga M, Kweka EJ, Mnyone LL, et al. Knowledge, attitudes, and practices about malaria and its control in rural northwest Tanzania. Malar Res Treat. 2010;2010:794261.

37. Tyagi P, Roy A, Malhotra MS. Knowledge, awareness and practices towards malaria in communities of rural, semi-rural and bordering areas of east Delhi (India). J Vector Borne Dis. 2005:42:30-5.

38. Lindsay SW, Emerson PM, Charlwood JD. Reducing malaria by mosquitoproofing houses. Trends Parasitol. 2002;18:510-4.

39. Kirby MJ, Ameh D, Bottomley C, Green C, Jawara M, Milligan PJ, et al. Effect of two different house screening interventions on exposure to malaria vectors and on anaemia in children in the Gambia: a randomised controlled trial. Lancet. 2009;374:998-1009.

40. Ogoma SB, Kannady K, Sikulu M, Chaki PP, Govella NJ, Mukabana WR, et al. Window screening, ceilings and closed eaves as sustainable ways to control malaria in Dar es Salaam. Tanzan Malar J. 2009:8:221.

41. Munguambe K, Pool R, Montgomery C, Bavo C, Nhacolo A, Fiosse L, Sacoor $C$, et al. What drives community adherence to indoor residual spraying (IRS) against malaria in Manhiça district, rural Mozambique: a qualitative study. Malar J. 2011:10:344.

42. Frederick J, Saint Jean Y, Lemoine JF, Dotson EM, Mace KE, Chang M, et al. Malaria vector research and control in Haiti: a systematic review. Malar J. 2016;15:376

43. Chanda E, Ameneshewa B, Angula HA, litula I, Uusiku P, Trune D, et al. Strengthening tactical planning and operational frameworks for vector control: the roadmap for malaria elimination in Namibia. Malar J. 2015;14:302.

44. Musoke D, Karani G, Ssempebwa JC, Etajak S, Guwatudde D, Musoke MB. Knowledge and practices on malaria prevention in two rural communities in Wakiso District, Uganda. Afr Health Sci. 2015;15:401-12.

45. Rodríguez AD, Penilla RP, Rodríguez MH, Hemingway J, Trejo A, HernándezAvila JE. Acceptability and perceived side effects of insecticide indoor residual spraying under different resistance management strategies. Salud Publica Mex. 2006:48:317-24

46. Bamaga OA, Mahdy MA, Mahmud R, Lim YA. Malaria in Hadhramout, a southeast province of Yemen: prevalence, risk factors, knowledge, attitude and practices (KAPs). Parasit Vectors. 2014;7:351.

47. Eyobo MB, Awur AC, Wani G, Julla Al, Remijo CD, Sebit B, et al. Malaria indicator survey 2009, South Sudan: baseline results at household level. Malar J. 2014;13:45. 